\title{
Homing age influences the prevalence of aggressive and avoidance-related behaviour in adult dogs
}

\section{Jokinen, Olli}

2017-10

Jokinen, O , Appleby, D , Sandbacka-Saxen , S , Appleby , T \& Valros , A 2017 , ' Homing age influences the prevalence of aggressive and avoidance-related behaviour in adult dogs ' , Applied Animal Behaviour Science , vol. 195 , pp. 87-92 . https://doi.org/10.1016/j.applanim.2017.06.003

http://hdl.handle.net/10138/307995

https://doi.org/10.1016/j.applanim.2017.06.003

cc_by_nc_nd

acceptedVersion

Downloaded from Helda, University of Helsinki institutional repository.

This is an electronic reprint of the original article.

This reprint may differ from the original in pagination and typographic detail.

Please cite the original version. 


\section{Accepted Manuscript}

Title: Homing age influences the prevalence of aggressive and avoidance-related behaviour in adult dogs

Authors: Olli Jokinen, David Appleby, Sofi Sandbacka-Saxén, Tuulia Appleby, Anna Valros

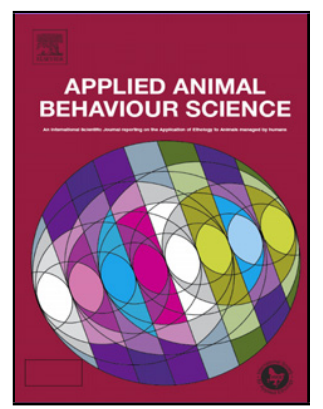

PII: S0168-1591(17)30180-6

DOI: http://dx.doi.org/doi:10.1016/j.applanim.2017.06.003

Reference: APPLAN 4474

To appear in:

APPLAN

Received date: 22-11-2016

Revised date: 4-6-2017

Accepted date: 6-6-2017

Please cite this article as: Jokinen, Olli, Appleby, David, Sandbacka-Saxén, Sofi, Appleby, Tuulia, Valros, Anna, Homing age influences the prevalence of aggressive and avoidance-related behaviour in adult dogs.Applied Animal Behaviour Science http://dx.doi.org/10.1016/j.applanim.2017.06.003

This is a PDF file of an unedited manuscript that has been accepted for publication. As a service to our customers we are providing this early version of the manuscript. The manuscript will undergo copyediting, typesetting, and review of the resulting proof before it is published in its final form. Please note that during the production process errors may be discovered which could affect the content, and all legal disclaimers that apply to the journal pertain. 


\title{
Homing age influences the prevalence of aggressive and avoidance-related behaviour in adult dogs
}

\author{
Olli Jokinen*, David Appleby ${ }^{\mathrm{b}, \mathrm{c}}$, Sofi Sandbacka-Saxén ${ }^{\mathrm{c}}$, Tuulia Appleby ${ }^{\mathrm{b}, \mathrm{c}}$, Anna Valros ${ }^{\mathrm{a}}$
}

a University of Helsinki, Faculty of veterinary medicine, Department of production animal medicine, PO Box 57, 00014 University of Helsinki, Finland

b University of Helsinki, Faculty of veterinary medicine, behaviour clinic, Small Animal Hospital, Koetilantie 2, Helsinki,

c $\quad$ AB Klinikka, Lummetie 7, 31400 Somero, Finland

* Corresponding author. Tel. +358 503025940

E-mail addresses: olli.jokinen@ fimnet.fi (O. Jokinen), appleby@abklinikka.com (D. Appleby),

sofi.sandbacka@fimnet.fi (S. Sandbacka-Saxén), tuulia.appleby@abklinikka.com (T. Appleby), anna.valros@helsinki.fi (A. Valros)

\section{Highlights}

- A questionnaire study on problem behavior in adult dogs in Finland was conducted

- Age of homing from domestic environments and problem behaviors were associated

- Dogs homed after 8 weeks had higher prevalence of aggressive and avoidance behavior

- Homing dogs raised in a domestic environment no later than at 8 weeks is indicated

\begin{abstract}
Homing puppies before 8 weeks has been associated with lower instance of avoidance and types of aggression in adult dogs. The current study aimed to further assess the impact of homing age on these behaviours in adult dogs. Finnish dogs provide an interesting population for this further study, as based on the clinical experience of the co-authors, puppies in Finland are predominantly reared in domestic maternal
\end{abstract}


environments before first homing, which is was not the case in the countries where previous studies have been performed.

Online questionnaire-based data on frequencies of problematic behaviours $(n=3689)$ were analysed using Chi-Square, comparing adult dogs homed at 6-7 weeks (6-7), 8 weeks (8), 9-12 weeks (9-12) and 13-16 weeks (13-16). $31 \%$ were 6-7, $41 \%$ 8, $23 \%$ 9-12, $5 \%$ 13-16. If an overall association was observed, pairwise comparisons between homing age groups were conducted. All of the dogs included in the study came from domestic maternal environments, where the puppies were kept in the breeders' living quarters. Homing age was associated with avoiding, growling and snapping at unfamiliar people when away from the home environment ( $\mathrm{p}=0.004, \mathrm{p}=0.02$ and $\mathrm{p}=0.008$, respectively); avoiding, barking at, growling at and snapping at unfamiliar people visiting the home $(\mathrm{p}=0.02, \mathrm{p}=0.02, \mathrm{p}=0.04$ and $\mathrm{p}=0.03$, respectively $)$ and barking at unfamiliar dogs when away from the home environment $(\mathrm{p}=0.001)$. With one exception, dogs homed later than 8 weeks, namely during weeks 9-12 and 13-16, had higher than expected prevalence of avoidance and aggressive behaviour than dogs homed at other ages. The exception being that for the measure, barking at unfamiliar dogs away from the home environment, there were higher than expected values in dogs homed at 8 and 13-16 weeks and lower in dogs homed at 6-7 and 9-12weeks. This research supports the view that homing age is associated with instances of avoidance behaviour and some types of aggression in adult dogs.

Abbreviations: SBTB = Snap, bite or try to bite; A classification of a type of problem behaviour used in the study.

Keywords: Canine, behaviour, homing age, aggression, dog, puppy 


\section{Introduction}

According to the WSPA (2008), dog ownership in the UK exceeds 6 million animals. Dogs are also the most common pets in USA households and second only to cats in numbers (Schaumberg, 2012). In addition, dogs are used for many professional and recreational purposes. However, canine behavioural problems have been reported to be very common, both in the UK and USA (O'Farrell, 1992; Mills and Mills, 2003). The benefits commonly associated with dog ownership (e.g. health benefits to the owner and positive influence on psychosocial development of preadolescent children) (Headey et al., 2002; Van Houtte \& Jarvis, 1995) (e) can be compromised as a result of unwanted or maladaptive behaviours on the part of the dog (Serpell, 1996). In addition to strains on the human-animal bond, some behavioural issues can compromise overall welfare of companion pets (Landsberg et al. 2012).

The most common cause of referral to canine behavioural consultant in the UK and USA is aggression, especially aggression towards unfamiliar people (Beaver, 1994; Landsberg et al., 2012). In the USA, aggression is also the most common reason for dogs being euthanised at an early age and in general, more pets are euthanised for behavioural reasons than for all medical reasons combined (Landsberg et al., 2012). Understanding how predisposing factors for aggression and other canine behaviour problems can be avoided provides a better basis for the dog-human relationship, reduces the risk of welfare issues for both dogs and their human companions, as well as reducing the potential for the untimely euthanasia of dogs.

The ability to cope in a varied and changing environment (subsequently referred to as "confident" behaviour) is influenced by both genetic and environmental factors (Fox, 1978; Markwell \& Thorne, 1987; Webster, 1997). In respect of environmental factors it is generally accepted that dogs have a developmental sensitive period for socialisation between approximately 2.5 - 14 weeks of age (Freedman et al., 1961; Scott \& Fuller, 1965; Fox, 1978). Exposures during this period are said to help prevent behavioural issues in adult dogs (Scott \& Fuller, 1965; Fox, 1978). However, more recent studies have found the socialisation window to be 
much shorter and peak between 4-8 weeks of age (Pfaffenberger \& Scott, 1976; Markwell \& Thorne, 1987; McCune et al., 1995; Appleby, 1999). In particular, the most important weeks for exposure to benign stimuli may be weeks 3 to 5 (Pluijmakers et al., 2010). In light of these findings, the impact of breeding environment may be even more important to the development of adult behaviors than previously believed (Appleby et al., 2002; Plujimakers et al., 2003; Thompson, 2009).

In 1965 Scott and Fuller proposed that dogs should be homed between six and eight weeks so that the puppy would have time to adjust to their new homes and owners while the socialisation period is still ongoing. There is clinical evidence suggesting that dogs that receive insufficient exposure to social and non-social stimuli during the sensitive period are more likely to develop fear responses to novel stimuli as adults (Appleby, 1993). More precisely, an increase in adult fear and avoidance problems as well as aggressive behaviour have been reported if the dog is homed at 8 weeks of age or later (Jagoe, 1993; Appleby et al., 2002). Although there are various motivations for aggressive behaviour, in many cases they are caused by fear and thus potentially linked to avoidance behaviour (Mertens, 2002; Haug, 2008). When a dog uses aggression as a defence and perceives it to be successful through learning, the behaviour might become more generalised, overt and can occur at a lower threshold (Campbell, 1975; Appleby et al., 1993; Lindsay, 2000; Mertens, 2002; Haug, 2008).

The link between some types of aggressive and avoidance behaviour and homing age has been previously shown in other countries, where the puppies came from various maternal environments (Appleby et al., 2002, Pierantoni et al., 2011). In light of these previous studies, we hypothesised that homing no later than at 8 weeks would have a positive effect on reducing the occurrence of aggressive and avoidance behaviour in adult dogs in a population where most puppies are perceived to be reared in a domestic maternal environment. The purpose of this study was to determine if there was an association between homing age and aggressive and /-avoidance behaviour in adult dogs in Finland. Finnish dogs provided an interesting study population as, based on clinical experience by co-authors, it was hypothesised that most puppies in Finland 
are bred in a domestic maternal environment before going to their first homes. This allows for a possibility to further increase the understanding of the effect of the domestic maternal environment.

\section{Materials and methods}

\subsection{Data collection}

These data were collected using an online questionnaire hosted by the University of Helsinki (E-lomake).

The survey was available for one month in the spring of 2011 and distributed through the Finnish Animal Welfare Research Centre's website, various Finnish social media networks, and dog owner discussion forums. The questionnaire consisted of 14 questions and question charts that were divided in two sections. The first section focused on descriptives (e.g. age, breed, sex), details concerning the dog's background (e.g. age of acquisition, living environment before acquisition) and socialisation practises (e.g. the number of times the dog visited different rural and urban environments as a puppy). The second section included questions about different types of problem behaviours in the form of tick-box tables or items phrased as "yes/no" questions. There was no definition of aggression or avoidance in the questionnaire nor were the respondents expected to give one. Instead, the items focusing on aggressive and avoidance behaviours were presented in tables as statements describing various behaviours such as "My dog growls at veterinarians" or "My dog growls at unfamiliar dogs outside the home". The owner was able to match the given problem behaviour with corresponding situation by ticking the corresponding box. This study focused on the questionnaire data related to aggressive and avoidance-related behaviour in different situations as indicated in Table 1.

For the purposes of this study we defined a respondent's dog to exhibit aggressive behaviour if it was reported to growl, snap, bite or try to bite (later SBTB) in any situation given in the questionnaire. Moreover, a respondent's dog was defined to exhibit avoidance-related behaviour if it was reported to evade contact with or hide from any situation or person (e.g. veterinarians or unfamiliar people visiting the dog's home).

\subsection{Selection of participants}


The total number of questionnaires, each containing the answers pertaining to an individual dog, was 6659 . From the gross data, dogs with uncertain backgrounds, such as animal shelters or rescue organisations, were excluded, as were dogs not obtained from their breeders as a first homing. Because the onset of some behaviour problems occurs at the time of social maturity (Borchelt, 1984; Thompson, 2009) dogs that were reported to be less than one year old were excluded. Dogs homed after 16 weeks of age were excluded since such a late homing is not considered common practice and the reasons for late homing, such as health, were unknown to the authors. Dogs homed earlier than 6 weeks were excluded due to the small sample size and uncommonly young homing age. Dogs that were not homed but raised by their breeders were also excluded. From the remaining cases, $92.4 \%$ of dogs were found to have been raised in the breeder's home if retention in a separate room was included. These dogs were excluded and only dogs that were raised in the breeder's actual living quarters before homing ( $78 \%$ of the cases) were selected. After application of the exclusion criteria, the actual number of questionnaires analysed was 3689 .

\subsection{Data analysis}

These data were analysed using IBM SPSS Statistics version 22. The data were divided into four groups based on homing age, 6-7 w, $8 \mathrm{w}, 9-12 \mathrm{w}$ and 13-16 w respectively, which resulted in groups with relatively equal sized populations. In addition, this division made it possible to compare the most frequently reported homing age $(8 \mathrm{w})$ with incrementally increased or decreased homing age categories. Problem behaviours (shown in Table 1) were cross-tabulated with homing age and possible difference between observed and expected prevalence were tested using Pearson's chi-square test. Each test only included dogs reported by their owner to have encountered the situation in question, e.g. met unfamiliar dogs in home environment. Thus, the sample size varied between questions. If an overall association was observed, pairwise comparisons between homing age groups were conducted. The resultant $\mathrm{p}$-values from these pairwise comparisons were corrected using the Bonferroni-method.

\section{Results}




\subsection{Descriptive data}

A total of $3689 \operatorname{dogs}(48,3 \%$ male $-12,9 \%$ castrated, $51,7 \%$ female $-14,4 \%$ sterilised) were included in the analysis. In total, 227 breeds were reported. A large number of breed variants were combined due to the fact that some owners categorised breed more specifically than others, e.g. some stated coat type. For simplicity, similar breeds were combined, e.g. rough-coated and smooth-coated Dachshunds, resulting in 111 breeds. The four most common breeds were mixed breed (7,6\%), Collies $(3,4 \%)$, German Shepherds $(3,1 \%)$ and Dachshunds (2,8\%). The age range was 1-16 years, the mean age being 4,5 years (s.d. 2,9). The distribution of dogs within the different homing age groups is shown in Table 2.

\subsection{Associations between homing age and problem behaviour related to aggression and avoidance}

\subsubsection{Reactions to people unfamiliar to the dog when away from the home environment} Homing age was associated with avoiding (Pearson $\left.\operatorname{chi}^{2}(3): 13.2, n=3480, \mathrm{p}=0.004\right)$, growling at (Pearson $\left.\operatorname{chi}^{2}(3): 9.82, \mathrm{n}=3453, \mathrm{p}=0.02\right)$ and snapping at, biting and trying to bite (SBTB) (Pearson $\mathrm{chi}^{2}(3): 11.8, \mathrm{n}$ $=3453, \mathrm{p}=0.008$ ) unfamiliar people when away from the home environment. (Fig. 1). Pairwise comparisons showed significant differences in the prevalence of this behaviour when comparing homing age groups 6-7 w and $8 \mathrm{w}$ to the 13-16 $\mathrm{w}$ group. The 13-16 $\mathrm{w}$ group showed higher prevalence of avoiding unfamiliar people outside the home than the earlier homing age groups $(6-7$ vs $13-16 \mathrm{p}=0.02 ; 8$ vs $13-16 \mathrm{p}=0.02)$. The $13-16$ $\mathrm{w}$ group also showed a higher prevalence of growling at unfamiliar people outside the house than the $8 \mathrm{w}$ group ( 8 vs 13-16 p = 0.04). Moreover, a higher prevalence of SBTB was observed in dogs homed at 13-16 w compared to earlier homing age groups $(6-7$ vs $13-16 \mathrm{p}=0.005 ; 8$ vs $13-16 \mathrm{p}=0.005)$.

In pairwise comparisons, the 9-12 w group was not significantly different from the other groups.

No association between homing age and barking at unfamiliar people outside the home was observed ( $\mathrm{p}>$ $0.1)$. 


\subsubsection{Reactions to people unfamiliar to the dog visiting the dog's home}

Homing age was associated with barking at $\left(\right.$ Pearson $\left.\mathrm{chi}^{2}(3): 10.1, \mathrm{n}=3489, \mathrm{p}=0.02\right)$, growling at (Pearson $\left.\operatorname{chi}^{2}(3): 8.36, \mathrm{n}=3474, \mathrm{p}=0.04\right)$, SBTB (Pearson $\left.\mathrm{chi}^{2}(3): 8.77, \mathrm{n}=3474, \mathrm{p}=0.03\right)$ and avoiding unfamiliar people visiting the home (Pearson $\left.\mathrm{chi}^{2}(3): 9.97, \mathrm{n}=3486, \mathrm{p}=0.02\right)($ Fig. 1)

Pairwise comparisons revealed that the 9-12 w group showed a higher prevalence of barking at unfamiliar people visiting the home compared to the 6-7 w group (6-7 vs 9-12 $\mathrm{p}=0.02)$. The 9-12 $\mathrm{w}$ group also showed a higher prevalence of growling at unfamiliar people visiting the home than the $8 \mathrm{w}$ group $(8 \mathrm{vs} 9-12 \mathrm{p}=$ 0.05). The 13-16 w group showed a higher prevalence of SBTB unfamiliar people visiting the home than the $8 \mathrm{w}$ and $9-12 \mathrm{w}$ groups $(8 \mathrm{vs} 13-16 \mathrm{p}=0.02 ; 9-12 \mathrm{vs} 13-16 \mathrm{p}=0.04)$

The pairwise comparisons did not show significant differences between the specific homing age groups in the prevalence of avoiding unfamiliar people visiting the home $(p>0.1$ for all).

\subsubsection{Reactions to unfamiliar dogs away from the home environment}

Chi-square tests showed an association between homing age and barking at unfamiliar dogs outside the home $\left(\right.$ Pearson chi $\left.^{2}(3): 17.3, \mathrm{n}=3522, \mathrm{p}=0.001\right)($ Fig. 1)

In the pairwise comparisons, the group homed at 6-7 w showed the lowest prevalence of this behaviour when compared to the other groups (6-7 vs $8 \mathrm{p}=0.03 ; 6-7$ vs $9-12 \mathrm{p}=0.002 ; 6-7$ vs $13-16 \mathrm{p}=0.04)$.

No association between homing age and avoiding, growling at or SBTB unfamiliar dogs outside the home were observed (overall $\mathrm{p}>0.1$ for all).

\subsubsection{Reactions to familiar people, familiar dogs and veterinarians}

No significant associations were found between homing age and avoiding, barking at, growling at or SBTB familiar people. No associations between homing age and avoiding, barking at, growling at or SBTB familiar dogs were observed. In addition, no associations between homing age and avoiding, barking at, growling at or SBTB veterinarians were observed (overall $\mathrm{p}>0.1$ for all). 


\section{Discussion}

In this study increased age of homing appeared to be connected to a higher prevalence of aggressive/avoidance behaviour towards unfamiliar people and dogs, both inside and outside adult dogs' homes and, as such, support previous findings. Appleby et al. (2002) showed that adult dogs obtained at 8 weeks of age or later from a mixture of maternal environments were more likely to show aggression to unfamiliar people outside their home. Sterry et al. (2005) found that dogs that attended puppy classes, and homed before 8 weeks, were less likely to be aggressive towards or avoid unfamiliar dogs and less likely to growl at or avoid visitors in the home than dogs that attended puppy classes but homed at 8 weeks or later. In the present study, even though a statistical difference was not found between each age group in the pairwise comparisons, a consistent numerical increase in the incidence of avoiding, growling and SBTB at unfamiliar people, when away from the home environment, was seen in dogs homed later than 8 weeks. Similar results have been shown in various other studies (Jagoe, 1993; McGreevy and Masters, 2008; O'Sullivan et al., 2008). Thompson (2009) and O'Sullivan et al. (2008) reported higher incidence of problem behaviour in dogs homed at 8 weeks or later. Based on previous studies, several authors of books on the topic have concluded the ideal age for homing to be 6 (Freeman, 1991) or 6-8 weeks (Serpell, 1995; Scott and Fuller, 1965; Lindsay, 2000). However, previous studies consisted of mixed samples of kennel, or equivalent, and domestic bred dogs. The present study considers the effect of homing age on the incidence of aggressive and avoidance behaviour when the dog's early environment was domestic. The behaviour of barking towards unfamiliar dogs was less represented in dogs homed $<8$ weeks of age. This is counter intuitive because the popular view is that puppies should remain with their mother and littermates for longer to reduce the risk of problematic behaviour towards other dogs through adequate socialisation. As the motivation for the symptom of barking is not known, further study is required. A possible explanation is that dogs in the younger homing age group had fewer expectations when encountering unfamiliar dogs, resulting in lower instances of barking 
related to frustration when on leash. Conversely, it might indicate broader socialisation with other dogs at an early age occurred or that the earlier homing group were generally more confident. It could also be the consequence of the attitudes and practices of owners likely to take younger puppies being different to the rest of the population of dog owners. It is often assumed that there is a risk of puppies not learning to relate to familiar dogs properly when they are separated from their dam and siblings "early" (Westgarth et al., 2012). In our study, the age of homing had no effect on behaviour towards familiar dogs, which would indicate that a later homing age did not enhance the social behaviour of the dog within its own environment

The most essential part of the sensitive period for social behaviour lasts until 8-10 weeks of age which is when the weaning would take place in natural conditions (McCune et al., 1995). According to different sources (Freedman et al., 1961; McCune et al., 1995) the dog's susceptibility to forming fear responses to novelty starts at 7-10 weeks, as a result the puppy's social openness declines. Taking recent findings in consideration, it may therefore be suggested that late (> 8 weeks) homing might detrimentally delay the puppy's opportunity to adjust to the broad range of benign stimuli it will encounter beyond the domestic environment and experiences provided by the breeder. Further research on the subject using longitudinal studies would be beneficial.

The present study shows that, in Finland, it is common (78\%) to breed dogs within the breeder's domestic environment (93\%, if within-home puppy facilities, such as a separate room, are not excluded, as they were in this study), rather than non-domestic environments, such as kennels and outbuildings. This, in addition to the large sample size, provided the opportunity for a statistically significant insight into the adult behaviour of dogs raised in domestic maternal environments, in contrast to the studies with smaller sample sizes and with dogs in the sample originating from non-domestic environments (eg. Pierantoni et al., 2011, Appleby et al., 2002). It has been demonstrated that non-domestic breeding conditions, that provide inadequate social and environmental stimuli, may predispose dogs to developing problem behaviours (Appleby et al., 2002; Jagoe, 1993). This study indicates that, in terms of minimizing the risk of aggressive, and avoidance 
behaviour, postponing homing until after 8 weeks even when the dogs are raised in domestic environment, is not recommended. It needs to be underlined, however, that we have no data regarding the stimulation and socialization provided in the maternal environments, other than it was domestic and further studies are required to show the effect of homing age from environments where the breeder is proactive in these areas.

The breed distribution in this study seemed to represent the breeds in Finland well. Six of the most represented breeds in these data can also be found in the Finnish Kennel Clubs registry statistics for ten most popular breeds in Finland in 2011. However, some of the breeds were not represented in these data in proportion to their popularity in Finland. These included some of the most popular hunting breeds (e.g. Finnish hounds, Norwegian elkhounds and Swedish elkhounds) as well as some popular companion breeds (e.g. Miniature Schnautzers and Tibetan spaniels). This may be due to the fact that the questionnaire was distributed mainly through social media, which may not have reached all dog owners evenly. As the dataset included a large number of breeds (> 200), many represented by a low number of dogs, we could not study the effects of breed as such, nor was it the aim of the paper. However, the data suggested that some breeds might be worthwhile further study. One breed of potential interest was the chihuahua, which had a slightly later homing age, an average 9.9 weeks, as compared to 8.3 for all other breeds, as well as a high frequency of avoidance and aggression-related problem behaviours, as reported by Sandbacka (2015).

Barking in various situations was associated with different homing ages in this study. Dogs bark in different contexts, not only as a warning or a defensive gesture (Bleicher, 1962; Serpell \& Jagoe, 1995; Bradshaw \& Nott, 1995; Beaver, 1999). Although we could not define the motivation for barking in this study it has practical implications, as many owners find it an unwanted behaviour. In addition, barking often co-occurred in association with behaviours more clearly indicative of aggression. This could mean that the symptom was frequently defensive in nature. Similarly there are a variety of motivations for aggressive behaviour. This study did not interpret the motivation for these behaviours, although clinical experience suggests aggression, in the form of defence, and avoidance behaviour are often alternative or co-occurring coping strategies for 
fear (Campbell, 1975; Appleby et al., 1993; Lindsay, 2000; Mertens, 2002; Haug, 2008; Landsberg, 2012).

This observation was the reason why both aggression and avoidance were included in the study.

Furthermore, these behavioural categories have previously been shown to be linked to experiences during a puppy's early experience (Jagoe, 1993; Appleby et al., 2002; Thompson, 2009; Pierantoni et al., 2011)

In terms of minimizing the risk of aggressive and avoidance behaviour, according to the present study, it is beneficial to home puppies at the age of 8 weeks, if the breeder raises them in a domestic environment. Although the homing age group 6-7 w showed similar results, an even lower numerical prevalence of most of the problem behaviours was observed in dogs homed at 8 weeks. Since there is variation in breed characteristics (Campbell, 1974; APBC, 1994-2005) and the duration of socialisation period between different breeds may vary (Fox 1972), more research is needed in order to achieve breed specific guidelines for homing ages.

\section{Conclusion}

In this study we have demonstrated an association between homing age and some types of aggressive/avoidance behaviour in adult dogs. The study indicates that the prevalence of these problems is higher in puppies raised in a domestic environment and homed after 8 weeks of age, compared to homing at or before 8 weeks. Overall this study suggests the ideal homing age for puppies raised in a domestic environment is no later than 8 weeks.

\section{Conflict of interest statement}

The authors declare no conflict of interest. 


\section{Acknowledgements}

The authors would like to thank all the dog owners who participated in the study. We would also like to thank Nelli Gartman for her input in creating the questionnaire. Appleby's analysis of the questionnaire results was funded by Finnish Veterinary Foundation, Helvi Knuuttila grant. (ETTS.fi) 


\section{References}

Association of Pet Behaviour Counsellors, 1994-2012. Annual review of cases. http://www.apbc.org.uk/apbc/data Accessed 6.4.2016

Appleby, D.L., 1993. Socialisation and habituation. In: Fisher, J. (Ed.), The Behaviour of Dogs and Cats. Stanley Paul, London, pp. 24-40.

Appleby, D.L., 1999. The relationship between canine aggression and avoidance behaviour, and early experience. MSc-thesis, Anthrozoology Institute, University of Southampton New College.

Appleby, D.L., Bradshaw, J.W.S., Casey, R.A., 2002. Relationship between aggressive and avoidance behaviour by dogs and their experience in the first six months of life. Vet.Rec. 150, 434-438.

Beaver, B.V., 1994. Owner complaints about canine behavior. J Am Vet Med Assoc 204 (12), pp. 1953-5

Bleicher, N., 1963. Physical and behavioral analysis of dog vocalizations. Am J Vet Res 24, 415-426.

Borchelt, P.L., 1984. Development of behavior of the dog during maturity. In: Anderson, R.S. (Ed.), Nutrition and Behaviour in Dogs and Cats. Pergamon Press, Oxford, pp. 189-197.

Bradshaw, J. W., Nott, H. M. 1995. Social and communication behaviour of companion dogs. In: Serpell, J. (Ed.), The domestic dog: Its evolution, behaviour and interactions with people, Cambridge University Press, Cambridge, UK, pp. 115-130.

Campbell, W.E., 1975. Behavior Problems in Dogs. American Veterinary Publications Inc., California.

Fox, M., 1978. The Dog: Its Domestication and Behaviour. Garland STPM Press, New York.

Freedman, D.G., King, J.A., Elliot, O., 1961. Critical period in the social development of dogs. Science 133, $1016-1017$.

Haug, L.I., 2008. Canine aggression toward unfamiliar people and dogs. Vet Clin Small Anim23, 1023-1041 
Headey, B., Grabka, M., Kelley, J., Reddy, P., Tseng, Y.P., 2002. Pet ownership is good for your health and saves public expenditure too: Australian and German longitudinal evidence. Australian Social Monitor 5(4), 93.

Jagoe, J.A., 1993. Behaviour problems in the Domestic Dog: A retrospective and prospective study to identify factors influencing their development. PhD Thesis. University of Cambridge.

Landsberg, G.M., Hunthausen, W., Ackerman, L., 2012. Canine aggression. In: Landsberg, G.M., Hunthausen, W., Ackerman, L. Handbook of Behaviour problems of the dog and cat. 3. ed. Saunders, London: 129-150.

Lindsay, S.R., 2000. Handbook of applied dog behavior and training: vol 1 : adaptation and learning. Iowa State University Press, Ames.

McCune S, McPherson J, Bradshaw JWS. Chapter 6: Avoiding problems: The importance of socialisation. In: Robinson I. (ed.) The Waltham Book of Human-Animal Interaction: benefits and responsibilities of pet ownership. 1. ed. Pergamon Press, Oxford 1995: 71-86.

McGreevy, P.D., Masters, A.M., 2008. Risk factors for separation-related distress and feed-related aggression in dogs: additional findings from a survey of Australian dog owners. Appl Anim Behav Sci 109, 320-328.

Mills, D., Mills, C., 2003. A survey of the behaviour of UK household dogs. Fourth International Veterinary Behaviour Meeting Proceedings, p. 93.

Nott, H.M.R., 1992 Behavioural development of the dog. In: Thorne, C., The Waltham book of dog and cat behaviour. BPCC Wheatons 1td., Exeter, Great Britain, pp 65-78.

Markwell, P.J., Thorne, C.J., 1987. Early behavioural development of dogs. J Small Anim Pract 28, 984-991. 
Mertens, P. A., 2002. Canine Aggression. In: Horwitz, D. F., Mills, D. S., Heath, S., BSAVA Manual of Canine and Feline Behavioural Medicine. British Small Animal Veterinary Association, Quedgeley.

O'Farrell, V., 1992. Manual of canine behaviour. 2. ed. p. British Small Animal Veterinary Association (BSAVA), Cheltenham.

O'Sullivan, E.N., Jones, B.R., O'Sullivan, K., Hanlon, A.J., 2008. The management and behavioural history of 100 dogs reported for biting a person. Appl Anim Behav Sci 114, 149-158.

Overall, K., 1997. Clinical Behavioural Medicine for Small Animals. Mosby, St Louis.

Pfaffenberger, C. J., Scott J. P., 1976. Early rearing and testing. In: Guide Dogs for the Blind: Their Selection, Development and Training, ed. Pfaffenberger, C.J., Scott, J.P., Fuller, J.L., Ginsburg, B.E., Bielfelt, S.W., pp 13-37. Amsterdam, Elsevier.

Pierantoni, L., Albertini, M., Pirrone, F., 2011. Prevalence of owner-reported behaviours in dogs separated from the litter at two different ages. Vet Rec 169, 468.

Pluijmakers, J., Appleby, D. L., Bradshaw, J.W.S., 2003. Sensitive periods in the development of behavioural organization in the dog and the role of emotional homeostasis, Proceedings of the 4th International Veterinary Behavioural Meeting, No: 32, 18th-20th August 2003, Caloundra, Australia, pp. $119-126$.

Pluijmakers, J. J., T. M., Appleby, D.L., Bradshaw, J.W.S., 2010. Exposure to video images between 3 and 5 weeks of age decreases neophobia in domestic dogs. Appl Anim Behav Sci 126, 51-58.

Sandbacka, S. 2015. Undvikande och aggressivt beteende mot främmande människor hos hundar i Finland. Licentiate's thesis. University of Helsinki, Faculty of Veterinary Medicine.

Schaumberg, L. (ed.) 2012. American Veterinary Medical Association: U.S. Pet Ownership \& Demographics Sourcebook, AVMA. 
Scott, J.P., Fuller, J.L., 1965. Genetics and the Social Behaviour of the Dog. University of Chicago Press, Chicago.

Serpell, J., 1995. The Domestic Dog its evolution, behaviour and interactions with people. Cambridge University Press, Cambridge, UK.

Serpell, J., Jagoe, A., 1995. Early experience and the development of behaviour. In: Serpell, J. (Ed.), The Domestic Dog: Its Evolution, Behaviour and Interactions with People. Cambridge University Press, Cambridge, UK, pp. 79-102.

Serpell, J., 1996. Evidence for an association between pet behaviour and owner attachment levels. Appl Anim Behav Sci 47, 49-60

Sterry, J., Appleby, D., Bizo, L., 2005. The relationship between measures of problematical behaviour in adult dogs and age of first exposure outside the first owners' home and attendance at puppy classes. Proceedings of CABTSG study day. Birmingham, UK.

Thompson, K.F., 2009. The effects of early environment and upbringing during the first year on the development of behaviour problems in the dog: A longitudinal study. Unpublished Msc dissertation. University of Southampton Library.

Van Houtte, B.A., Jarvis, P.A., 1995. The role of pets in preadolescent psychosocial development. J Appl Dev Psychol, 16(3), 463-479.

Webster, S.D., 1997. Being sensitive to the sensitive period. In: Proceedings of the First International Conference on Veterinary Behavioural Medicine, pp. 20-27. Potters Bar, Universities Federation for Animal Welfare.

Westgarth, C., Reevell, K., Barclay, R., 2012. Association between prospective owner viewing of the parents of a puppy and later referral for behavioural problems. Vet Rec 170, 517. 
World Society for Protection of Animals, 2008. Stray animal control practises (Europe).

http://www.fao.org/fileadmin/user_upload/animalwelfare/WSPA_RSPCA\%20International\%20stray \%20control\%20practices\%20in\%20Europe\%202006_2007.pdf . Accessed 24.5.2017 
Fig. 1: Reactions associated with homing age. The percentages of the dogs exhibiting the behaviour in their homing age groups are shown in the columns. If the homing age groups had a significant difference in the pairwise comparisons a different letter was assigned. Groups that had no such difference were assigned the same letter.

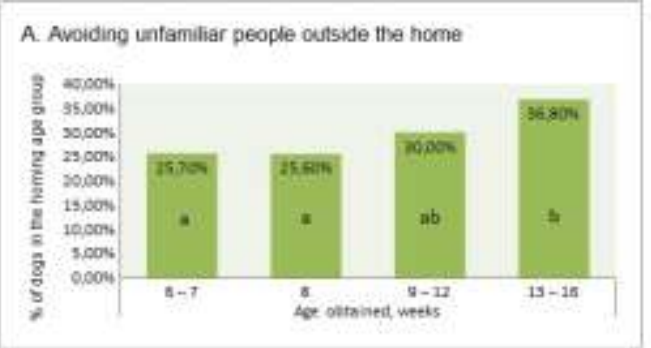

C. Snapping at, biting or tying to bite utamitar people outside the bone

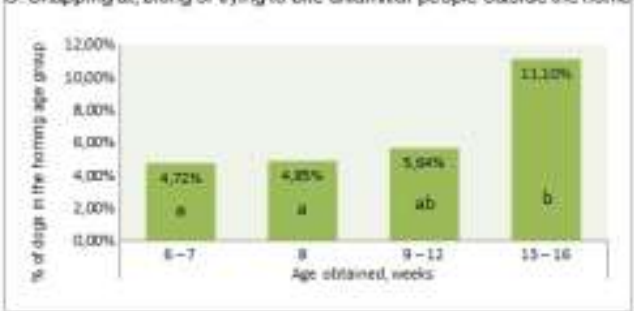

E. Barking at unfamitiar people at home

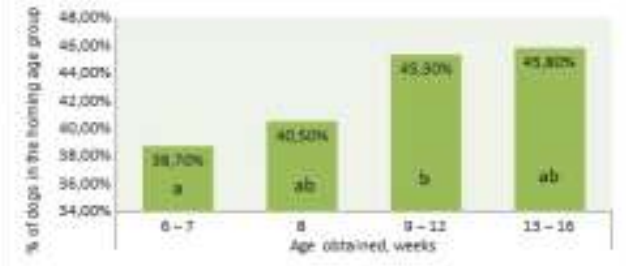

Q. Snapping at, biting or trying to bite unlamilar people at home

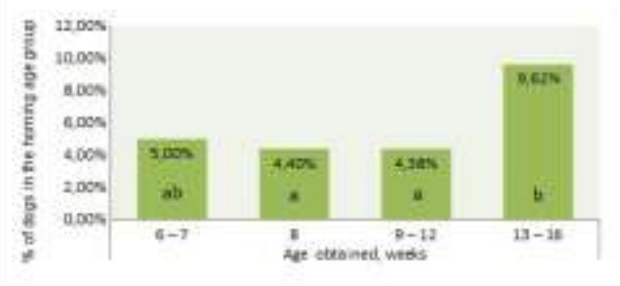

B. Growting et untamiliar people outside the home

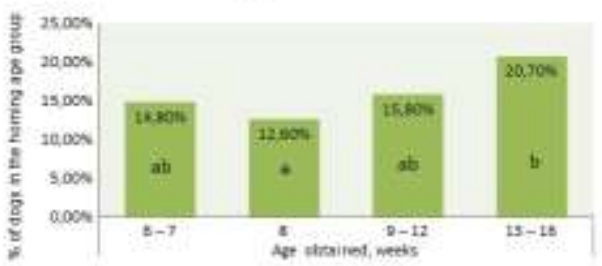

D. Avoiding unfamiliar people at home

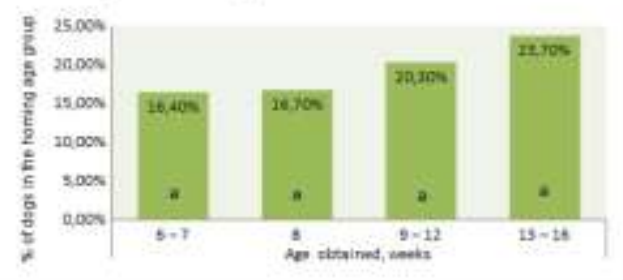

F. Groating at unfamitiar people at home

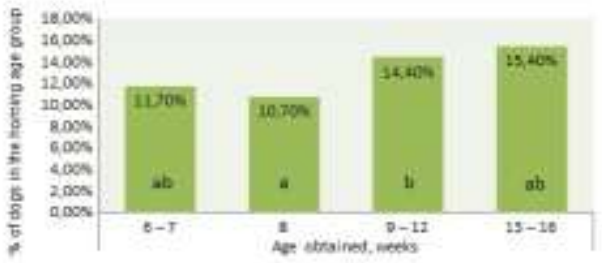

H. Barking at unfemilar dogs outside the home

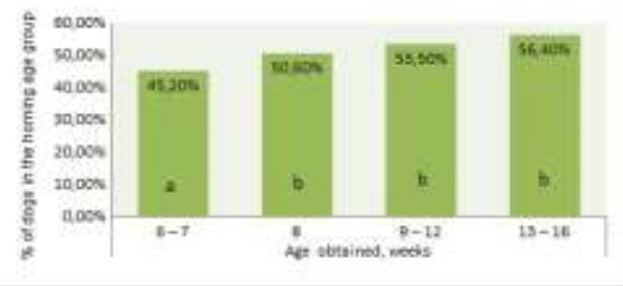


Table 1: Behaviours and corresponding situations tested for association to homing age.

\begin{tabular}{|c|c|c|c|}
\hline \multirow{6}{*}{$\begin{array}{c}\text { Homing age } \\
\text { vs. }\end{array}$} & \multirow{3}{*}{$\begin{array}{l}\text { Inside the } \\
\text { dog's home }\end{array}$} & $\begin{array}{l}\text { Familiar* } \\
\text { people }\end{array}$ & \multirow{3}{*}{$\begin{array}{l}\text { Avoiding } \\
\text { Barking }\end{array}$} \\
\hline & & $\begin{array}{l}\text { Familiar* } \\
\text { dogs }\end{array}$ & \\
\hline & & $\begin{array}{l}\text { Unfamiliar* } \\
\text { people }\end{array}$ & \\
\hline & \multirow{3}{*}{$\begin{array}{l}\text { Outside the } \\
\text { dog's home }\end{array}$} & $\begin{array}{l}\text { Unfamiliar* } \\
\text { people }\end{array}$ & \multirow{3}{*}{$\begin{array}{l}\text { Growling } \\
\text { Snapping at, biting or trying to bite (SBTB) }\end{array}$} \\
\hline & & $\begin{array}{l}\text { Unfamiliar* } \\
\text { dogs }\end{array}$ & \\
\hline & & Veterinarian & \\
\hline
\end{tabular}

* in relation to the $\mathrm{dog}$ 
Table 2: Homing ages analysed

\begin{tabular}{|c|c|c|c|}
\hline Homing age (weeks) & Frequency & Percent & Cumulative percent \\
\hline 6 & 42 & 1,1 & 1,1 \\
7 & 1115 & 30,2 & 31,4 \\
8 & 1509 & 40,9 & 72,3 \\
9 & 368 & 10 & 82,2 \\
10 & 196 & 5,3 & 87,6 \\
11 & 81 & 2,2 & 89,8 \\
12 & 214 & 5,8 & 95,6 \\
13 & 38 & 1 & 96,6, \\
14 & 36 & 1 & 97,6 \\
15 & 17 & 0,5 & 98 \\
16 & 73 & 2 & 100 \\
Total & 3689 & 100 & \\
\hline
\end{tabular}

